Gábor Pusztai

\title{
Caraïbische literatuur voor studenten in Debrecen
}

\author{
Interview met Michiel van Kempen
}

In 2016 is je Helman-biografie van 863 pagina's verschenen. Waarom heb je juist over Helman een biografie geschreven?

Met Albert Helman begint de moderne Nederlands-Caraïbische literatuur, iemand die voorop liep, óók als je zijn werk vergelijkt met dat van schrijvers uit de Franse of Engelse Caraïben. Hij is de schrijver van de eerste historische roman over de slavernij in de Nederlandse taal (De stille plantage, 1931), maar hij heeft nog zo ontzettend veel méér gedaan. Hij was de nestor van de Surinaamse letteren, en iedereen werd door hem geïnspireerd of zette zich juist tegen hem af. Het is ook echt een figuur geweest op het grensvlak van koloniale en postkoloniale tijd: alle issues van postkolonialiteit kun je uitleggen aan de hand van zijn werken en zijn doen en laten. Ik vond hem bovendien interessant omdat hij ook componist is geweest, en politicus, en journalist, en taalkundige, en wat is hij eigenlijk NIET geweest behalve sportman, dansinstructeur en hotelkok? (Maar hij heeft wel 3 kookboeken uitgegeven, terwijl hij zelf nog geen ei kon bakken!)

Hoe kwam je in contact met de Caraïbische literatuur?

Vraag me liever: hoe kom je ervan af? Onlangs las ik De Toverberg van Thomas Mann, Het boek der herinneringen van Pétér Nádas en Kaputt 
van Curzio Malaparte en toen dacht: er is nog zoveel verpletterend moois buiten het Caraïbisch gebied. Soms schrik ik er zelf van dat ik er al 35 jaar mee bezig ben. Dat kwam zo: toen ik nog jong, mooi en onweerstaanbaar was, haha, werkte ik in Suriname als docent Nederlands. Dat was begin jaren '80. Tot mijn verbazing was het curriculum daar zo ongeveer gelijk aan wat er in Nederlandse scholen gedoceerd wordt. Absurd natuurlijk in een tropenland. Men gebruikte Literaire Kunst van Lodewick, een boek uit 1947.

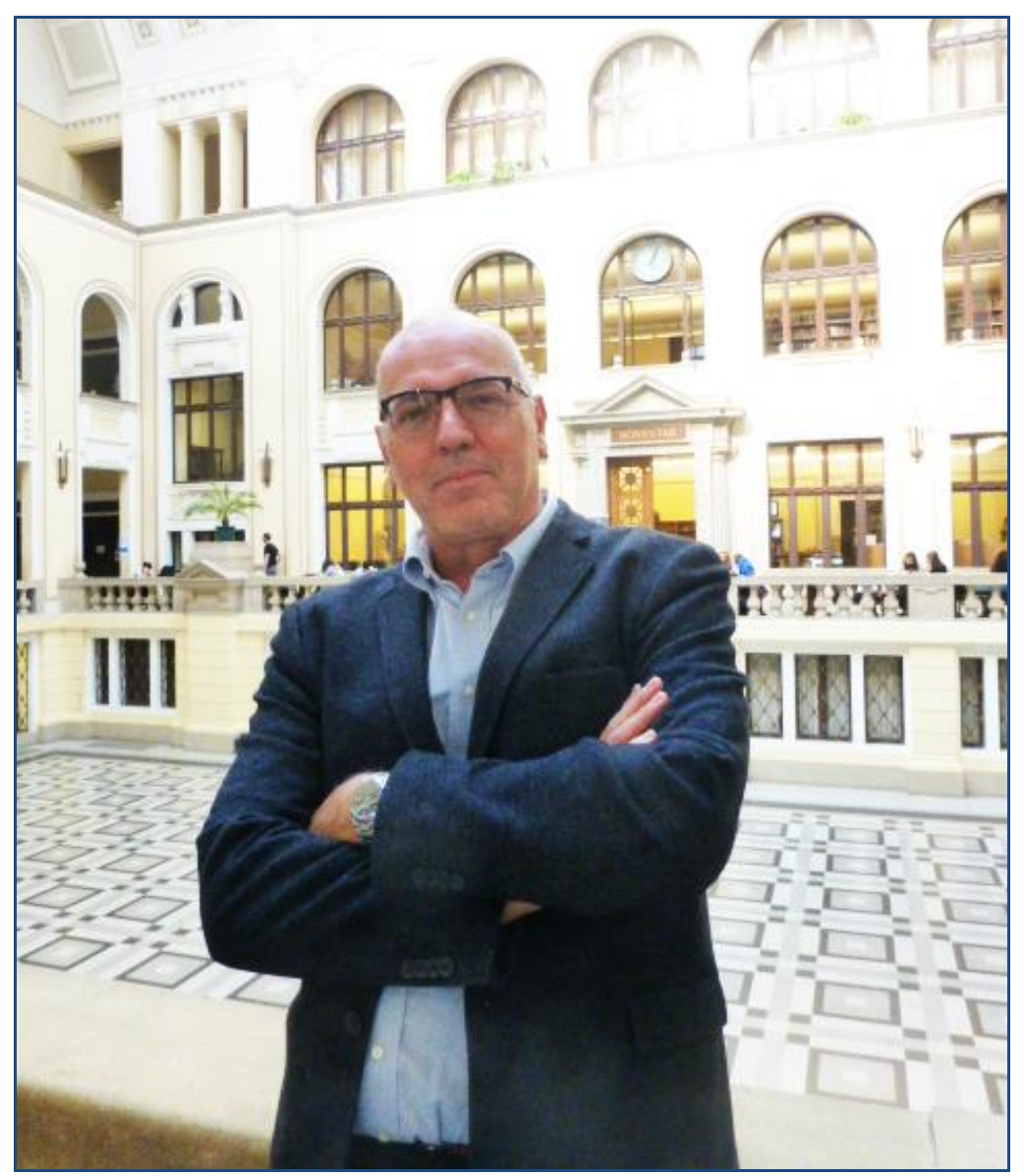

Michiel van Kempen in oktober 2018 aan de Universiteit Debrecen 
En voor de literatuur gebruikte men een paar pagina's van aan elkaar geniete stenciltjes. Wat een treurnis, ik vond het zo erg voor die kinderen. Ik was juist nieuwsgierig naar wat schrijvers in Suriname te vertellen hadden, ik vond dat hún verhalen en hún poëzie in de klas behandeld moesten worden, dus ik vroeg ze ook om te komen voordragen. Maar ja, het werkt alleen goed als je ook een behoorlijk literatuurboek hebt in de klas en dat was er niet. En hoe kun je nu een gevoel van eigenwaarde opbouwen in een jong, onafhankelijk land als je je eigen geschiedenis en cultuur niet kent? Dus daar is het wat mij aangaat allemaal begonnen: er moest materiaal komen voor de leerlingen en dan begin je teksten te verzamelen, erover te schrijven, ook in de dagbladen enz. En later zijn dan bloemlezingen en essays en een Surinaamse literatuurgeschiedenis in Nederland verschenen. Dat is dan stap twee: het uitdragen van die cultuur, laten zien wat er daarginds aan interessants wordt geschreven. Want die teksten maken niet alleen deel uit van de Antilliaanse en Surinaamse cultuur, maar óók van de Nederlandse geschiedenis en cultuur. De koloniën en de koloniale geschiedenis hebben wij als Nederlanders geschapen en dan zullen we daar ook kennis van moeten nemen, en niet alleen oppervlakkig, maar ook analytisch en zelfkritisch. Ja, óók als we dan eens moeten slikken en een bitter glas hebben leeg te drinken. Want wat onze voorouders daarginds hebben uitgespookt was lang niet altijd fraai - to put it mildly. En dat gaat dan weer door in de Nederlandse omgeving, in de invloeden van de migrantenculturen die je overal om je heen ziet, vooral in de grote steden, maar ook op de tv, in de muziek, in het voetbal enz. enz.

Kun je zelf een voorbeeld geven van je eigen kritisch bezig zijn binnen het postkoloniale veld?

Ik sprak in juni van dit jaar de eerste Jit Narain Lezing uit in de Nieuwe Kerk in Den Haag. Mij was gevraagd om niet de poëzie van Jit Narain te analyseren maar in te gaan op de positie van Hindostanen in Suriname en Nederland. Toen ben ik maanden in de literatuur over dat onderwerp gedoken en toen kwam ik tot een merkwaardige ontdekking: in alle geschiedenissen van Suriname kun je lezen dat na de slaventijd de eerste Hindostaanse (Brits-Indische) contractarbeiders op 5 juni 1873 in Suriname arriveerden met het schip de Lalla Rookh. Die datum wordt elk jaar gevierd, dit jaar de herdenking van 145 jaar Hindostaanse immigratie. Maar de Brits-Indische contractarbeid in Suriname is al vijf jaar eerder 
begonnen, dit jaar dus niet 145 maar 150 jaar geleden! En de eerste BritsIndische ooit geboren op Surinaamse grond dateert van 1872, dus ook al van vóór 1873! Dat heb ik in die lezing in Den Haag betoogd.

\section{Waarom wonen zo veel Surinamers in Nederland?}

De grootste groepen immigranten trokken vlak vóór en vlak ná de onafhankelijkheid in 1975 naar Nederland. Die zagen een toekomst in Suriname niet zitten. Deze mensen hebben vrolijk voortgefokt. Volgens het Centraal Bureau voor de Statistiek telde Nederland 349.022 Surinaamse Nederlanders in 2016. 177.720 mensen behoren tot de eerste generatie, ze zijn in Suriname geboren en daarna naar Nederland gekomen, 171.302 mensen behoren tot de tweede generatie; ze zijn in Nederland geboren. Latere generaties worden niet meer meegeteld als Surinamers. In Suriname zelf woonden, in juli 2016, 585.824 Surinamers. In totaal zijn er dus 934.846 Surinamers. Maar ja, er wonen er ook aardig wat in de USA en ik ben ook Surinamers tegengekomen in Canada, in Dubai, in België, in Malta, in Rusland. En wie weet, sinds Surinaamse paarden meedoen aan wedstrijden in Boedapest, zijn er ook wel Surinamers in Hongarije neergestreken.

Hoe is de integratie van Surinamers in Nederland? Heeft dit invloed op de literatuur?

In de eerste jaren na de grote immigratie van rond 1975 kwamen bepaalde groepen Surinamers negatief in het nieuws, met name door drugsverslaving. Maar daar hoor je nu niets meer over. Conclusie: binnen één generatie is een enorme groep immigranten perfect geïntegreerd. Ze bezetten nu posities binnen alle geledingen van de samenleving, ze studeren, zijn huizenbezitters, zijn vertegenwoordigd in allerlei politieke geledingen. In de sport waren ze al vroeg nadrukkelijk aanwezig (Gullit, Davids, Rijkaard, Seedorf enz., Patrick Kluivert is nog altijd topscorer van het Nederlands elftal), Nederland heeft wereldkampioenen met Surinaamse roots in de atletiek en het zwemmen gehad, en in de journalistiek en amusementswereld doen ze nadrukkelijk mee. Schilders krijgen tentoonstellingen in grote musea. En nu zie je dat Nederlands-Caraïbische schrijvers ook serieus meedoen voor de literaire prijzen: Antoine de Kom kreeg de VSB-poëzieprijs, Radna Fabias de C. Buddingh'-prijs voor poëzie, Etchica Voorn de Opzij Literatuurprijs, Jit Narain de Jit Narain 
Cultuurprijs en Astrid Roemer de hoogste Nederlandse literaire prijs, de P.C. Hooftprijs.

Wat is de rol en de positie van de Caraïbische literatuur binnen de Nederlandse literatuur?

Ik vind dat de Nederlandse literatuurkritiek over het algemeen het werk van Caraïbische auteurs met weinig kennis van zaken bespreekt, en in veel gevallen ten onrechte negeert. Maar goed, zoals ik al zei: die auteurs doen toch serieus mee in het prijzencircus. En je ziet ze ook met columns en ander werk in de belangrijkste kranten en tijdschriften. Je ziet niet zelden dat een auteur eerst een prijs krijgt en dan pas gerecenseerd wordt. Dat is natuurlijk een omkering van een normale volgorde.

Kun je hierover wat meer vertellen? Wordt Caraïbische literatuur stiefmoederlijk behandeld door literatuurhistorici? Hoe was dat? Hoe is dat nu? Is er een verandering? Is er een tendens (meer interesse, of juist minder dan vroeger)?

Vroeger vond je twee namen in de literatuurgeschiedenissen: Albert Helman en Cola Debrot. Als je kijkt naar de laatste twee delen van de grote literatuurgeschiedenis van de Taalunie, de delen geschreven door Jacqueline Bel en Hugo Brems, dan kun je moeilijk volhouden dat de (post)koloniale literaturen stiefmoederlijk behandeld zijn. Die hebben zelfs méér plaats gekregen dan bij de start van het project voorzien was, dat was bij een vergadering in het gebouw van de Eerste Kamer in Den Haag: toen werd het standpunt ingenomen dat die literaturen alleen een plaats zouden krijgen in zoverre ze raakvlakken hadden met de Nederlandse schrijvers. Een belachelijk, eurocentrisch en arrogant standpunt natuurlijk. Daar hebben mijn voorganger Bert Paasman en ik toen ook duidelijk stelling tegen genomen.

Dit betekent nog niet dat postkoloniale literaturen ook aan de Nederlandse universiteiten een vaste plaats hebben verworven. Ik heb wel eens een rondje gemaakt langs de universiteiten om te zien of er plaats voor ingeruimd kon worden. Overal dezelfde reactie: geen ruimte, geen geld, past niet in het onderzoeksprofiel. Allemaal manieren om te zeggen: we zijn er zelf niet mee bezig, we weten er niets vanaf en het interesseert ons dus geen fuck. Maar als het niet past in je onderzoeksprofiel, nou pas dan dat onderzoeksprofiel aan! In de Verenigde Staten vormen black studies 
de grootste studierichting! In Nederland is het nog altijd droevig conservatief gesteld met die studies. Postkoloniale literatuur is het schaamlapje van de neerlandistiek geworden. In personeelswervende advertenties zie je altijd staan: bijzondere belangstelling voor de postkoloniale gebieden van Nederland is gewenst. In Leiden was de literatuur van Indië en ZuidAfrika altijd belangrijk bij mensen als Peter van Zonneveld, Eep Francken, Gerard Termorshuizen enz. Dus toen er een nieuwe hoogleraar Nederlandse letterkunde moest komen, stond er een hele alinea over postkoloniale literatuur in de advertentie. En wie werd er benoemd? Yra van Dijk, voortreffelijke wetenschapper, maar zij had nog nooit 1 letter over de Oost of de West geschreven. En zo'n benoeming komt toch ook doordat die benoemingscommissies zelf geen enkel benul hebben van postkoloniale vraagstukken. Die hebben allemaal de Bijbel gelezen en één boek van Gerard Reve en misschien De schaamte voorbij van Anja Meulenbelt. Godzijdank, zeg ik er direct bij, heeft Yra van Dijk als hoogleraar in Leiden die gebieden wel direct meegenomen in haar aandachtsveld voor onderwijs en onderzoek. Dat geeft hoop.

2003 is je vijf kilo zware, 1396 pagina's tellende literatuurgeschiedenis van Suriname in twee delen verschenen. Jij bent dus DE kenner van de Surinaamse literatuur. In die tijd dat je in Suriname zat was je al begonnen met het verzamelen van materiaal voor je literatuurgeschiedenis. Als ik me niet vergis, ben je ook met een recorder het oerwoud ingegaan om orale literatuur te verzamelen. Hoe ging dat?

Ik wilde te weten komen wat er nu daadwerkelijk nog levend was aan orale literatuur. Dus niet alleen zien wat er in oude studies stond, maar ook: hoe wordt er nu nog verteld en gezongen? Toen ben ik naar twee plaatsen gegaan: één aan de Boven-Suriname onder de Saramakaner bosnegers (zoals ze zichzelf noemen), dat is in het hart van het regenwoud van Suriname, en een Indiaans dorp aan de monding van de Marowijnerivier in het oosten tegen de grens met Frans Guyana aan, allebei bestemmingen waarvoor je uren moet varen na het laatste punt waar de berijdbare weg stopt. En toen heb ik dagenlang onder die mensen geleefd, opnames gemaakt en precies beschreven welke genres er nog verteld worden, welke liederen nog worden gezongen, welke dansen opgevoerd, wat ze betekenen enz. Dus een diachronische beschrijving van orale literatuur 'op één moment'. Mijn belangrijkste informanten waren mensen met een ontzaglijke kennis van hun volk, mensen van hoge leef- 
tijd, ze zijn allebei inmiddels overleden. Naar Monica Koloi, een Indiaanse vrouw van over de 80 uit het dorp Galibi, heb ik mijn eigen dochter vernoemd.

Wat is de situatie van de Caraïbische literatuur in het Caraïbisch gebied en in Nederland?

Ik weet niet of je bedoelt of er een relatie is tussen die vijf kilo literatuurgeschiedenis en de literatuur zelve. Wie weet gaan schrijvers er gebukt onder. Maar goed, de Surinaamse literatuur in vergelijkend perspectief Suriname-Nederland levert een merkwaardig uiteenlopend beeld op: in Suriname doen de oude dichters Michael Slory en Jit Narain het fantastisch maar verschijnt er héél weinig nieuwe literatuur voor volwassenen, op enkele auteurs van kort proza na: Rappa, Ruth San A Jong, Karin Lachmising, Sakoentela Hoebba. Maar er verschijnen wel heel veel kinderboekjes (ook weer nauwelijks boeken voor de wat oudere jeugd in de tienerleeftijd). In Nederland is er nu een nieuwe generatie schrijvers opgestaan, allemaal nieuwe namen: Karin Amatmoekrim, Clyde Lo A Njoe, Raoul de Jong, Shantie Singh, Diana Tjin, Johan Fretz, Radna Fabias, Chesley Rach, Chris Polanen, Dean Bowen, Michael Tedja, Etchica Voorn, Johan Herrenberg. Ze schrijven op hoog niveau en sommigen schrijven zelfs werk dat je academisch zou kunnen noemen. Ze scoren daar hoog mee in literaire kringen in Nederland, maar dringen nauwelijks door tot Suriname - op Karin Amatmoekrim na, over wie ook een televisiedocumentaire is gemaakt. Dus je zou kunnen zeggen dat de kloof tussen beide literaturen steeds breder wordt.

Met de voormalige Nederlandse Antillen ligt het net iets anders. De taalkloof scheidt de eilanden van Nederland: op de eilanden is het bijna allemaal Papiaments wat de klok slaat, ook daar veel kinderliteratuur en nauwelijks literatuur voor volwassen lezers (de Papiamentstalige Arubaan Jesse Tromp schrijft wel voor volwassenen). Schrijvers van Nederlandstalig werk zitten in Nederland en zijn bovendien bijna allemaal boven de 60, op enkele auteurs na als de Curaçaoënaars Eric de Brabander, Ronny Lobo en Diana Lebacs en de Arubaan Jacques Thönissen overigens ook allemaal boven de 60! Dus het lijkt erop dat de Nederlandstalige Antilliaanse literatuur op termijn zal verdwijnen, en er enkel een migrantenliteratuur over blijft. Enkele jongere dichters in Nederland zijn Gershwin Bonevacia, Quinsy Gario (vooral bekend als anti-Zwarte 
Piet-activist) en Radna Fabias die als een komeet omhoog is geschoten met haar debuut Habitus. Laten we ook niet vergeten dat er een heel nieuw genre is opgekomen met spoken word/rap. Typhoon, Gikkels, Zulile Blinker en Fresku, alle van (deels) Surinaamse afkomst, hebben landelijke bekendheid verworven.

Hoe is de situatie van het onderzoek naar de Nederlandse koloniale literatuur? Komt er een tweede generatie onderzoekers na Paasman, Termorshuizen, Van Zonneveld, Praamstra, Franken of zakt de interesse een beetje in? En hoe zie jij de toekomst ervan?

Dat is een lastige vraag. Er is na de genoemde generatie (en je noemt alleen mensen uit de hoek van de Nederlands-Indische letteren) wel een aantal nieuwe onderzoekers aangetreden, maar die is nog niet zo breed dat je al echt van een generatie of groep kunt spreken. Jonge academici horen eerder tot de disciplines van de meer maatschappelijke vraagstukken met aandacht voor slavernij, zwarte cultuur en black activism: mensen als Francio Guadeloupe, Dienke Hondius, Hebe Verrest, Anouk de Koning, Rivke Jaffe, Karwan Fatah Black, Valika Smeulders, Aminata Cairo, Mitchell Esajas, Margo Groenewoud, Margriet Fokken, Jaswina Elahi, Kirtie Algoe, Lonneke Geerlings, Ellen de Vries, Daphina Misiedjan. Dat zijn dus historici, antropologen, sociologen. Over jonge aanwas van mensen in de literatuurstudie maak ik me wel eens zorgen, ook omdat er in Leiden een kaalslag is geweest: veel wetenschappers die met Indië bezig waren zijn met pensioen. Rick Honings zit daar nog wel en ook de nieuwe hoogleraar Yra van Dijk trekt de postkoloniale literatuur nadrukkelijk in haar aandachtsveld. Gelukkig zijn de leerstoelen Indische letteren en Zuid-Afrikaanse letteren aan de UvA opnieuw bezet door respectievelijk Remco Raben en Margriet van der Waal. Hopelijk leveren die een nieuwe aanwas van onderzoekers op. Binnen de Indische letteren zijn er recent enkele interessante promoties geweest van jonge academici: Paul Bijl schreef over de omgang met het Nederlandse koloniale verleden aan de hand van koloniale fotografie en Lisanne Snelders schreef over Hella Haasse, Tjalie Robinson, Pramoedya Ananta Toer en de politiek van de herinnering. Dus dan zie je al direct een groot verschil met de oudere generatie: nu gaat het over herinneringscultuur en dat soort research heeft een stevig theoretisch fundament. De oudere generatie zat veel dichter bij tempo doeloe, onderzocht meer realia, het waren stuk voor stuk goede sprekers en schrijvers die graag het publiek wilden trakteren 
op smakelijke anekdotiek. Het gevaar van de nieuwe generatie is natuurlijk dat een sterker academische toon het oude publiek dat zo massaal afkwam op de colloquia van Indische Letteren, niet aanspreekt. De vergrijzing daar is een grote zorg. En het jaarlijkse colloquium Surinamistiek bestaat niet meer, waardoor de bindende kracht voor het prachtige tijdschrift voor Surinamistiek Oso wegviel; het verschijnt helaas niet meer. Bij mijn leerstoel zijn er nu 4 mensen gepromoveerd en 13 werken nog aan een proefschrift, maar slechts enkele zijn jong en het gaat niet alleen om letterkundig onderzoek, maar soms ook cultuurhistorisch onderzoek.

Gaat volgens jou het klassieke literatuuronderwijs (ook aan de universiteiten) ten onder? Komt daarvoor ,cultural studies” of iets anders in de plaats? Waar gaat de ontwikkeling naartoe?

Het klassieke literatuuronderwijs gaat niet ten onder, we láten het ten onder gaan. En dan heb ik het niet over oud, suffig, hiërarchisch georiënteerd taalonderwijs, over muffe didactiek, die mag van mij ook weg. Ik heb het over grondige kennis van de talen. Om redenen van economie en efficiëntie zijn er al allerlei studies verdwenen en is er gehakt in de studie van de zogenaamd 'kleine talen', zoals het Hongaars, het Bulgaars, het Fins. Hongaars kun je niet meer aan een Nederlandse universiteit studeren. Een taal uit de heilige Europese Gemeenschap: weg, streep erdoor! Maar het Hongaarse volk is een oud Europees volk dat in het hart van de Europese cultuur staat. Met gemeenschappelijke waarden met andere Europese volkeren, maar óók met een eigen cultuur en taal. Als wij elkaar fundamenteel willen verstaan, dan moeten wij niet genoegen willen nemen met een oppervlakkig cultuurbesef voorzien van een licht Amerikaans vernisje en met kennis die niet veel verder gaat dan wat er staat op het schermpje van ons mobieltje. Dan moeten we ons grondig in taal en cultuur van een volk willen verdiepen en kúnnen verdiepen.

Het is moeilijk te voorspellen welke kant het opgaat met de talenstudies. Maar de studentenaantallen zijn wel zorgelijk laag in Nederland: er waren in 20186 eerstejaars Nederlands aan de Vrije Universitiet in Amsterdam, inmiddels is de studie zelfs helemaal verdwenen! Als ik me nu beperk tot de neerlandistiek, dan vraag ik me af: maakt de neerlandistiek zichzelf te weinig noodzakelijk? Edward Said zei het al in 2003: de filologie heeft een stoffig imago, maar in feite is de filologie de meest wezenlijke en creatieve van de verklarende wetenschappen. Er zijn allerlei 
wetenschappen en wetenschapjes om de filologie heen komen staan die stukken van het terrein afsnoepten: cultural studies, mediastudies, gender studies, ga maar door. En neerlandici gaan daarin mee: het laatste boek van de hoogleraar moderne Nederlandse letterkunde in Amsterdam gaat over de geschiedenis van de DAF-fabrieken en het laatste boek van de hoogleraar in Utrecht over de roerige jaren '60. Prima boeken, maar die hadden evengoed geschreven kunnen worden door historici. Ik ben zelf een groot voorstander van het ontsluiten van literatuur binnen een sociaalhistorische context, maar waar neerlandici goed in zijn, wat hun kracht uitmaakt is de analyse van teksten. Waarom is De stille kracht van Louis Couperus al 120 jaar lang een fantastisch boek? Dan kun je een heel verhaal beginnen over de koloniale Indische context, en over die siri spuwende Javanen en over de losbandige Emile van Oudijck. Prima. Maar het ís een fantastisch boek door de wijze waarop het geschreven is, door de taalvorm. En dáár komt de neerlandicus in beeld: die kan de kwaliteit van de tekst duidelijk maken. Als de analyse van de artistieke vorm er niet meer toe doet, dan is het liedje 'Brandend zand' van de onlangs overleden Anneke Grönloh ('Brandend zand/ verloren is het land/ en een leven vol gevaar') even geweldig als een sonnet van P.C. Hooft. Maar waar zijn we dan mee bezig? Dan heb je toch geen neerlandicus meer nodig, ja, misschien nog een brandweerman voor dat brandend zand, maar de neerlandistiek kan wel inpakken.

Je kent erg veel neerlandici, ook extra muros. Wat vind je van de interesse voor de literatuur uit de voormalige Nederlandse koloniën in de regio Midden-Europa (Polen, Tsjechië, Hongarije enz.)?

Voor zover ik dat kan overzien bestaat er een levendige belangstelling in Midden-Europa voor Nederlands-(post)koloniale literatuur, en die begrijp ik ook wel: in de positie daar 'in de periferie' van de neerlandistiek zitten veel overeenkomsten met de positie van de neerlandistiek in bijvoorbeeld Paramaribo of Willemstad of Oranjestad. Misschien dat Midden-Europese onderzoekers daarom ook een bijzondere sensitiviteit hebben voor de literatuur uit de voormalige Nederlandse koloniën; ik heb al heel mooie studies gelezen van wetenschappers uit Midden-Europa. Ik heb zelf de indruk dat als ik vertel over Surinaamse en Antilliaanse literatuur, dat nog meer snaren raakt in Midden- en Oost-Europa dan in Groningen of Tilburg. Hopelijk blijft die belangstelling ook onveranderd sterk. Je ziet natuurlijk wel dat de persoonlijke belangstelling van vakgroepsleiders een 
cruciale rol speelt. Ik ben al vaak in Hongarije geweest en ook in andere landen, maar nog nooit in steden als Zagreb, Sarajevo, Boekarest of Moskou; ik vrees dat de studenten daar over de postkoloniale culturen van Nederland dan ook niet veel te horen krijgen. (Aarzel dus niet mij te bellen, lieve mensen, nummer opvraagbaar bij de heer Pusztai!)

Maar ik begrijp dat de neerlandistiek in Midden-Europa ook onder druk staat. En erger nog: de Nederlandse Taalunie werkte daar zelf aan mee, door een malloot als de Vlaming Geert Joris als algemeen secretaris aan te stellen in 2012, die de structuur van internationale taalondersteuning zelf begon af te breken. Ik denk dat met Hans Bennis aan het roer de Taalunie een gezondere koers gaat varen: je verkoopt hem geen knollen voor citroenen maar hij heeft een groot hart voor de Nederlandse taal en de neerlandistiek extra muros. 